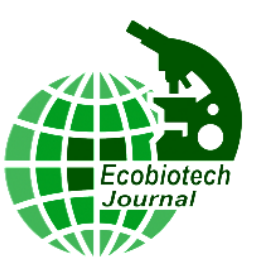

ЭКОВ

ОПРЕДЕЛЕНИЕ УРОВНЯ ЭКСПРЕССИИ

ГЕНОВ ФЕРМЕНТОВ СYР74 КУКУРУЗЫ ОБЫКНОВЕННОЙ (ZEA MAYS L.)

ПРИ ВЗАИМОДЕЙСТВИИ С ФИТОПАТОГЕНОМ PANTOEA ANANATIS LMG 20103

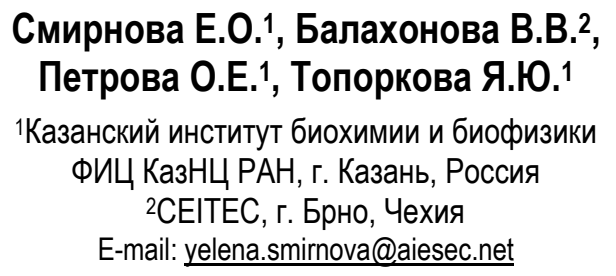

В работе была проведена оценка динамики экспрессии генов ферментов СYР74 у растений кукурузы обыкновенной (Zea mays L.) при инфицировании клетками фитопатогенной энтеробактерии Pantoea ananatis LMG 20103.

Ключевые слова: алленоксидсинтаза, гидропероксидлиаза. инфицирование, кукуруза, липоксигеназный каскад, ферменты СYP74, фитопатогены, экспрессия генов

\section{DETERMINATION OF GENE EXPRESSION LEVEL OF CYP74 ENZYMES IN CORN (ZEA MAYS L.) INFECTED BY PHYTOPATHOGEN PANTOEA ANANATIS LMG 20103}

Smirnova E.0.1, Balahonova V.V. ${ }^{2}$, Petrova O.E. ${ }^{1}$, Toporkova Y.Y. ${ }^{1}$

${ }^{1}$ Kazan Institute of Biochemistry and Biophysics FRC KazSC RAS, Kazan, Russia ${ }^{2}$ CEITEC, Brno, Czech Republic E-mail: yelena.smirnova@aiesec.net

In present work, dynamics of corn (Zea mays L.) CYP74 genes expression was evaluated upon infection with cells of the phytopathogenic enterobacteria Pantoea ananatis LMG 20103.

Keywords: allene oxide synthase, hydroperoxide lyase, infection, corn, lipoxygenase cascade, CYP74 enzymes, phytopathogen, gene expression

Поступила в редакичию: 06.05.2020

DOI: $10.31163 / 2618-964 X-2020-3-2-245-252$

\title{
ВВЕДЕНИЕ
}

У растений при формировании ответа на стрессовые факторы, в том числе инфицирование фитопатогенными бактериями, важная роль принадлежит ферментам семейства CYP74, которые являются ключевыми компонентами липоксигеназного каскада. К семейству CYP74 относятся четыре группы ферментов: алленоксидсинтазы (АОС), гидропероксидлиазы (ГПЛ), дивинилэфирсинтазы (ДЭС) и эпоксиалкогольсинтазы (ЭАС). Результатом работы этого каскада является образование биоактивных окисленных производных жирных кислот - оксилипинов. Данные соединения участвуют в регуляции процессов роста, развития, а также в формирование ответных реакций растительного организма на сигналы внешней среды [Itoh et al., 2002; Савченко и др., 2014; Toporkova et al., 2018].

Функции оксилипинов, синтезированных в алленоксидсинтазной и гидропероксидлиазной ветвях липоксигеназного каскада, хорошо изучены [Stintzi et al., 2000; Vancanneyt et al., 2001; Chen et al., 2011]. Метаболитами АОС ветви являются жасмонаты и циклосодержащие октадеканоиды. Меняя экспрессию генов, данные соединения регулируют рост и развитие растений, формирование цветков, контролируют фертильность и влияют на процесс фотосинтеза [Савченко и др., 2014]. Продуктами ГПЛ ветви являются летучие соединения, формирующие «запах зеленых листьев». Данные соединения играют важную роль в сложной сигнальной системе, обеспечивающей экологические взаимодействия растений с растениями и другими организмами [Vancanneyt et al., 2001]. Кроме того, при 
участии ГПЛ образуются травматин и травматиновая кислота, участвующие в борьбе с последствиями механических повреждений [Zimmerman et al., 1979]. AOC и ГПЛ присутствуют во всех изученных на данный момент цветковых растениях, в отличие от ДЭС и ЭАС, обнаруженных в растениях отдельных, филогенетически отдаленных видов.

К настоящему времени накоплено большое количество данных, характеризующих каталитические свойства ферментов CYP74 [Gorina et al., 2016; Toporkova et al., 2018; 2019]. Однако исследователи редко уделяют внимание экспрессии соответствующих генов в определенных условия, например, при взаимодействии с фитопатогенными микроорганизмами. Знания об экспрессии генов ферментов СYР74 у растений отдельных видов весьма отрывочны. В настоящее время возникла необходимость оценки функционирования всех представителей семейства СУР74 отдельного вида растений. Поскольку липоксигеназный каскад является эволюционно древним метаболическим путем, в результате ранней дивергенции у растений разных таксонов возможны различия в функционировании этого каскада, в том числе в динамике экспрессии соответствующих генов в разных условиях [Toporkova et al., 2018].

Целью нашей работы явилась оценка динамики экспрессии генов ферментов CYP74 у растений кукурузы обыкновенной (Zea mays L.) в результате инфицирования клетками фитопатогенной энтеробактерии Pantoea ananatis LMG 20103.

\section{.МАТЕРИАЛЫ И МЕТОДЫ}

Культура фитопатогенной энтеробактерии P. ananatis LMG 20103 была любезно предоставлена нам доцентом Е.А. Николайчиком из коллекции микроорганизмов Белорусского государственного университета (г. Минск). В работе была использована кукуруза обыкновенная (Z. mays) сорта «Катерина».

Клетки бактерий выращивали на среде LB [Гловер, 1988]. В отдельных экспериментах использовали полуселективную среду PA 20 [Goszczynska et al., 2006]. Для приготовления инокулята клетки бактерий дважды отмывали стерильным $0,9 \%$ раствором $\mathrm{NaCl}$ с последующим центрифугированием при 13000 об/мин в течение 5 минут, после чего ресуспендировали в эквивалентном объеме растворе хлорида натрия.

Оценку титра культур клеток проводили по количеству колониеобразующих единиц (КОЕ) в миллилитре культуры стандартным методом. Для этого суспензию клеток микроорганизмов последовательно разводили в $0,9 \%$ растворе $\mathrm{NaCl}$ в сериях десятикратных разведений. По 100 мкл соответствующих разведений $\left(10^{-3}, 10^{-5}, 10^{-7}\right)$ наносили в зависимости от эксперимента на чашки Петри с агаризованной средой LB, либо PA 20. Засеянные чашки Петри инкубировали в термостате при $28^{\circ} \mathrm{C}$. Подсчет КОЕ проводили через трое суток после посева на чашках, в которых вырастало от 20 до 200 колоний. Титр КОЕ в исходной культуре определяли по среднему числу колоний, выросших в разных сериях, с учетом степени разведения [Нетрусов и др., 2005].

Зерна кукурузы обрабатывали 10\% раствором препарата «Белизна» в течение 5 минут, раствором перманганата калия в течение 30 минут, после чего замачивали на 24 часа в дистиллированной воде. Для проращивания семена кукурузы оставляли в стеклянном сосуде при комнатной температуре $\left(20-25^{\circ} \mathrm{C}\right)$, ежедневно меняя воду. Через трое суток проростки помещали в среду Кнопа [Reski, Abel, 1985]. После образования второго листа растения использовали для инфицирования. Заражение растений осуществляли двумя способами: 1) 10 мкл бактериальной суспензии вводили в пазуху листа при помощи микрошприца 
(Hamilton, Швеция); 2) 30 мкл инокулята вводили непосредственно в жидкую минеральную среду, где находились корни растения. В первом случае в контрольные растения инъецировали 10 мкл стерильного $0,9 \%$ раствора $\mathrm{NaCl}$. Дополнительным контролем служили интактные растения. Во втором случае в контроль не вносили бактериальную суспензию.

Для определения распространения клеток P. ananatis LMG 20103 по тканям растения проводили высевы на агаризованную среду гомогенизированных тканей опытных растений. Отбор образцов инфицированных растений производили через 4, 24, 48 и 72 часа после заражения. Контрольные и опытные растения делили на три зоны: 1 зона - листья, 2 стебель, 3 зона - корни. Поочередно каждую часть растения растирали в ступке с добавлением $0,9 \%$ раствора $\mathrm{NaCl}$. Затем полученный растительный экстракт разводили в $0,9 \%$ растворе $\mathrm{NaCl}$ в трех сериях десятикратных разведений $\left(10^{-1}, 10^{-3}, 10^{-5}\right)$ и по 100 мкл из каждого разведения высевали сплошным газоном на агаризованную среду РА 20. Посевы инкубировали в течение трех суток при $28^{\circ} \mathrm{C}$.

Далее из листьев и корней кукурузы выделяли тотальную РНК с помощью коммерческого набора RNeasy Plant Mini Kit (Qiagen, CША) согласно протоколу производителя. После выделения препарат подвергали обработке ДНКазой (Qiagen, CША) согласно протоколу производителя. Качество выделенной РНК оценивали по спектрам электрофоретического разделения в агарозном геле после окрашивания бромистым этидием. Определение концентрации РНК проводили с помощью флуориметра Qubit (Invitrogen, США). Полученную РНК использовали в качестве матрицы для синтеза кДНК с помощью обратной транскриптазы M-MuLV (Fermentas, Литва) в соответствии со стандартным протоколом производителя. Анализ экспрессии генов проводили методом количественной ПЦР в режиме реального времени на приборе CFX96 Touch Real Time System (Bio-Rad Laboratories, США) с использованием 2,5-кратной готовой реакционной смеси, содержащей в составе краситель EVA Green (Syntol, Россия). Полученные данные представляют собой средние значения величин, полученных в трех независимых экспериментах, со стандартным отклонением.

\section{РЕЗУЛЬТАТЫ}

Инфицирование кукурузы бактериальными клетками происходило без выраженных симптомов. Было установлено, что титр ночной культуры $P$. ananatis LMG 20103 составлял $4 \times 10^{9} \mathrm{KOЕ/мл.} \mathrm{Таким} \mathrm{образом,} \mathrm{при} \mathrm{инфицировании} \mathrm{растения} \mathrm{уколом} 10$ мкл суспензии вносили $4 \times 10^{7}$ бактериальных клеток. После заражения высев из растительных тканей показал, что бактериальные клетки остаются жизнеспособными только в зоне листьев (рис. 1A).

Высев из 2-й (стебель) и 3-й (корни) зоны опытных растений не обнаружил присутствия бактерии, также, как и высев из всех трех зон у контрольных растений: и растений, инъецированных $0,9 \%$ раствором $\mathrm{NaCl}$, и интактных растений (данные не показаны). Таким образом, данный эксперимент показал, что в течение 48 часов бактериальные клетки остаются жизнеспособными в инфицированных покровах растений; при инокуляции в листья бактериальные клетки находятся в этой зоне, не проникая в другие. Это можно объяснить тем, что P. ananatis LMG 20103 - фитопатоген, который, в основном, поражает листья и побеги инфицированных растений [Coutinho et al, 2002]. Не исключено также влияние стадии развития растения и ограниченного времени для развития инфекционного процесса. 
Другие результаты были получены после инфицирования растений кукурузы через минеральную среду (рис. 1Б). Количество бактериальных клеток, внесенных с 30 мкл суспензии в ростовую среду растений, составило $6 \times 10^{7}$. Через двое суток клетки бактерии P. ananatis LMG 20103 обнаруживали в зоне корня и листьев. Высев на третьи сутки подтвердил данные о том, что бактерия, продолжая размножаться в тканях корней, активно осваивала зону листьев (рис. 1Б).
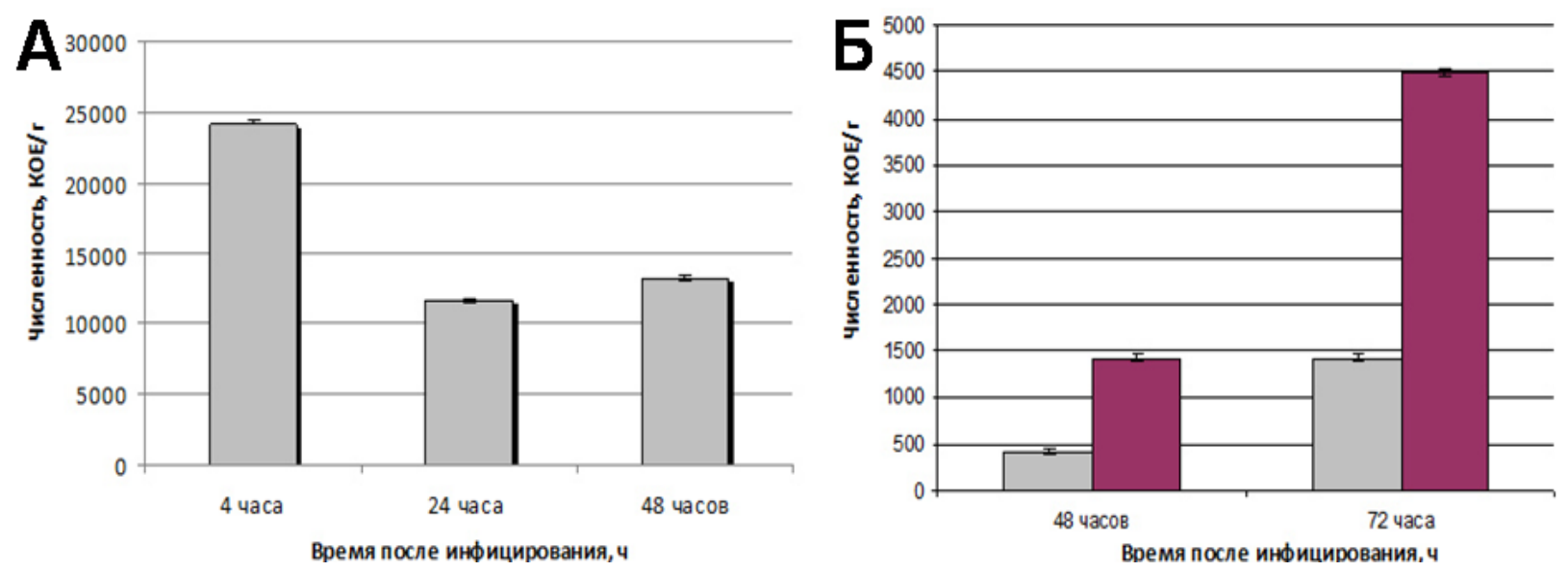

Рис. 1. А - количество КОЕ патогена, высеянных из листьев зараженных растений кукурузы in vitro. Б - количество КОЕ патогена, высеянных из листьев (светлый столбец) и корней (тёмный столбец) зараженных растений кукурузы in vitro через 48 и 72 часа.

Для оценки уровня экспрессии генов ферментов липоксигеназного каскада кукурузы была разработана экспериментальная платформа на основе ПЦР в реальном времени. Ключевым аспектом при этом являлся выбор референсных генов, относительно которых определялась динамика экспрессии целевых генов. В качестве «генов-кандидатов» выбирали гены белков, необходимых для функционирования живой клетки независимо ни от внешних условий, ни от клеточного цикла.

С использованием всемирной базы нуклеотидных последовательностей NCBI, а также базы данных web-pecypca (www.phytozome.com) в геноме кукурузы были выявлены последовательности возможных референсных генов актина и тубулина, а также ген глицеральдегид-3-фосфатдегидрогеназы (ГАФД). На каждый ген сконструировали по две пары специфичных праймеров (таблица). Однако в ходе ПЦР с использованием в качестве матрицы кДНК, полученных в результате реакций обратной транскрипции тотальных РНК, продукты амплификации ожидаемых размеров образовывались не со всеми парами праймеров (данные не представлены). Для последующих реакций ПЦР в реальном времени выбрали пары праймеров, с которыми образовывалось наибольшее количество продуктов амплификации ожидаемых размеров.

Соответствующие этим генам белки у растительных организмов присутствуют в нескольких изоформах, кодируемых гомологичными нуклеотидными последовательностями. Для подбора референсных генов оценивали содержание транскриптов не индивидуального гена, а суммарную экспрессию гомологичных генов одного класса белков (всех изоформ каждого класса). Поэтому для праймирования участков целевых генов выбирали области, идентичные для большинства гомологичных генов каждого класса белков.

Для определения возможности использования выбранных генов в качестве peференсных использовали приложение к Microsoft Excel - программу geNorm. Результатом 
такого анализа явилось ранжирование «генов-кандидатов» в зависимости от стабильности их экспрессии.

Выделение тотальной РНК проводили через 4, 8, 24 и 48 часов. На основе выделенной РНК получали библиотеки кДНК в результате реакции обратной транскрипции. Смеси кДНК использовали в качестве источников матриц для ПЦР в реальном времени с целью определения уровня экспрессии целевых генов. На каждый ген сконструировали две пары специфичных праймеров (таблица). Также как в случае с референсными генами, не со всеми парами праймеров в ходе ПЦР на смесях кДНК образовывались продукты амплификации ожидаемых размеров (не показано). Для последующих реакций ПЦР в реальном времени были выбраны пары праймеров, с которыми образовывалось наибольшее количество продуктов амплификации ожидаемых размеров.

На основе разработанной экспериментальной платформы проанализировали динамику экспрессии генов ZmHPL1, ZmAOS1 и ZmAOS2 как при инфицировании растений кукурузы клетками бактерии P. ananatis LMG 20103, так и при введении 0,9\% раствора $\mathrm{NaCl}$ заколом в ткани растения. Динамика экспрессии генов ГПЛ и АОС различается. Из литературы известно, что экспрессия генов ГПЛ должна возрастать в ответ на поранение. Мы наблюдали индукцию экспрессии ZmHPL1 через 8 часов при введении раствора $\mathrm{NaCl}$, тогда как при инфицировании - уже через 4 часа. Таким образом, можно сделать вывод, что ZmHPL1 непосредственно участвует в распространении сигналов о патогенезе в популяции, однако через 8 часов этот процесс прекращается. Это может происходить вследствие влияния патогена.

Динамика экспрессии генов АОС отличается от таковой гена ZmHPL1. При инфицировании (рис. 2А) максимальный уровень экспрессии гена ZmAOS1 наблюдался через 8 часов, тогда как при введении раствора $\mathrm{NaCl}$ - уже через 4 часа (рис. 2Б), что свидетельствует о возможном сдерживающем влиянии фитопатогена на экспрессию гена $Z m A O S 1$. Одинаковая динамика экспрессии гена ZmAOS2 при инфицировании и введении раствора $\mathrm{NaCl}$ через закол означает одинаковый ответ на поранение или $0,9 \%$ раствор $\mathrm{NaCl}$, однако более низкий (в 2 раза) уровень экспрессии ZmAOS2 через 4 часа после инфицирования также свидетельствует о сдерживающем влиянии фитопатогена на экспрессию гена ZmAOS2. Начиная с 24 часов, заметен спад уровня экспрессии всех исследуемых генов во всех случаях.
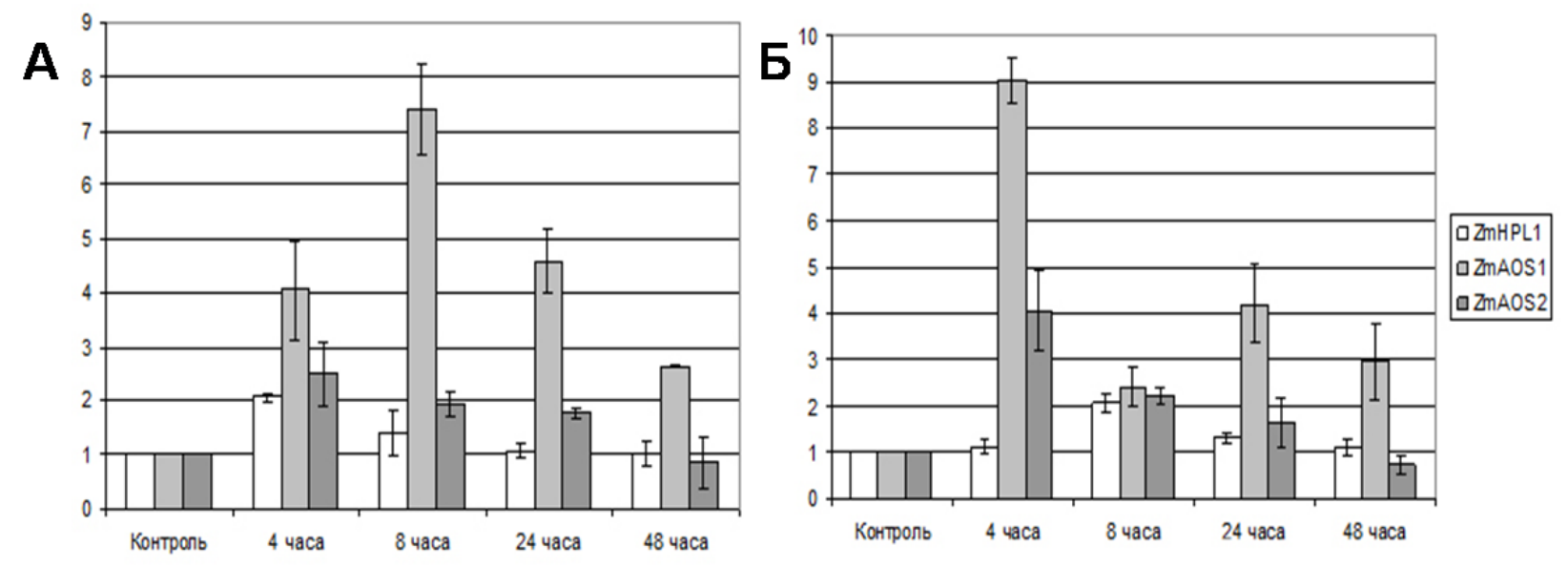

Рис. 2. А - изменение уровня экспрессии целевых генов ZmHPL1, ZmAOS1, ZmAOS2 при инфицировании растений кукурузы клетками $P$. ananatis LMG 20103. Б - изменение уровня экспрессии целевых генов $\mathrm{ZmHPL1}, \mathrm{ZmAOS1}, \mathrm{ZmAOS2}$ в результате инъекции в растения $0,9 \%$ раствора $\mathrm{NaCl}$. 


\section{ОБСУЖДЕНИЕ}

В литературе есть сведения о том, что продукты алленоксидсинтазной ветви липоксигеназного каскада взаимодействуют с сигнальными путями растительных гормонов: ауксина, гиббереллина, этилена, абсцизовой кислоты. Это расширяет спектр регулируемых этими метаболитами процессов. Метаболиты АОС ветви в адаптации растений к неблагоприятным факторам среды являются «переключателями» метаболизма растений с режима роста на режим защиты [Савченко и др., 2014]. Кроме того, существуют данные, что при стрессовых воздействиях метаболиты алленоксидсинтазной ветви являются главными регуляторами, изменяющими профиль экспрессии генов [Cheong et al., 2002]. Поэтому не удивительно, что при инфицировании кукурузы фитопатогеном возрастал уровень экспрессии генов алленоксидсинтаз. Однако экспрессия генов разных АОС отличалась. Возможно, это связано с доступностью субстрата.

Считается, что среди генов, экспрессия которых индуцируется 12-оксофитодиеновой кислотой (один из метаболитов АОС ветви), гены, вовлеченные в ответы растений на абиотические стрессоры, встречаются чаще; в то же время, среди генов, экспрессия которых индуцируется жасмоновой кислотой, преобладают гены, вовлеченные в ответы на биотические стрессоры [Савченоко, 2014]. Также известно, что любое механическое повреждение растения, даже прикосновение, в течение нескольких минут вызывает повышение уровня жасмонатов в вегетативных тканях [Buseman et al., 2006; Kourtchenko et al., 2007]. В наших экспериментах было показано, что поранение с использованием физиологического раствора, также вызывает повышение экспрессии генов алленоксидсинтаз, даже большее, чем инфицирование.

Таблица 1. Олигонуклеотидные праймеры референсных и целевых генов кукурузы

\begin{tabular}{c|c|c|c}
\hline Название & $\begin{array}{c}\text { Олигонуклеотидные праймеры } \\
\text { потенциально референсных генов } \\
\text { кукурузы }\end{array}$ & Название & $\begin{array}{c}\text { Олигонуклеотидные праймеры } \\
\text { целевых генов кукурузы }\end{array}$ \\
\hline ZmActF1 & GGTTCTATTCCAGCCATCCTTCATTG & ZmAOS1F1 & CACCCGCTCCTCACGCTCG \\
\hline ZmActF2 & CAATGGCACTGGAATGGTCAAGGCGGG & ZmAOS1F2 & CGGGTGGTGGCGGTCCTG \\
\hline ZmActR1 & CCCATGCCCACCATCACACCAG & ZmAOS1R1 & CGCCTGCTTCGCCACCG \\
\hline ZmActR2 & CCACCACTGAGGACAACATTACCG & ZmAOS1R2 & CGAGGAGAAGTTGGAGCGGAAGG \\
\hline ZmGapF1 & GCAATCCCGCCGTTCAACTATCCTG & ZmAOS2F1 & CAAGACGGACCTGTTCACGGGC \\
\hline ZmGapF2 & GTGCTAAAGCCTCCAACTCAGGGCG & ZmAOS2F2 & GGCGTTCAAGTGGCTCGTGTTC \\
\hline ZmGapR1 & CAGAACCCTTCCCAGTCACACAAC & ZmAOS2R1 & CGACGGTGCGAGAGGAGGTAGAAG \\
\hline ZmGapR2 & GAGGGACCATTCCAGCCTTCTTTG & ZmAOS2R2 & CGAGGACGCCCGCCG \\
\hline ZmTubF1 & CGAACTCTGAAGCTGACGACCCCTAG & ZmHPLF1 & GGCTGGTGGACAACTTCGGCTTC \\
\hline ZmTubF2 & GTCACTTGCTGCCTCCGCTTCCC & ZmHPLR1 & GGCTGGTGGACAACTTCGGCTTC \\
\hline ZmTubR1 & CGCAAAGCCAACCATGAAGAAGTG & ZmHPLF2 & CAGCACGGCATCGGCAAGAAG \\
\hline ZmTubR2 & CACGGTACTGCTGCGAGCCACG & ZmHPLR2 & CGCAGCATCTCGTACACCGTCG \\
\hline
\end{tabular}

О летучих метаболитах ГПЛ ветви липокигеназного каскада также известно достаточно много. Данные соединения принимают участие в формировании защитного ответа растения против фитопатогенных микроорганизмов и насекомых. Кроме того, летучие 
метаболиты ГПЛ ветви обладают бактерицидными и фунгицидными свойствами и сигнализируют интактным растениям об опасности [Bisignano et al., 2001]. Другие продукты ГПЛ ветви - травматин и травматиновая кислота очень быстро накапливаются в растительных тканях при их повреждении [Савченко и др., 2014]. Скорее всего, метаболиты ГПЛ ветви в определенном количестве присутствуют в растении конститутивно, поэтому в нашем эксперименте отмечено лишь незначительное повышение экспрессии гена ГПЛ.

\section{ФИНАНСОВАЯ ПОДДЕРЖКА}

Работы выполнена в рамках государственного задания Федерального исследовательского центра «Казанский научный центр Российской академии наук», с использованием приборной базы ЦКП-САЦ ФИЦ КазНЦ РАН (г. Казань).

\section{СПИСОК ЛИТЕРАТУРЫ}

1. Гловер Д. Клонирование ДНК. Методы. Москва: Мир, 1988. 538 с.

2. Нетрусов А.И., Егорова М.А., Захарчук Л.М. и др. Практикум по микробиологии. Москва: Академия, 2005. 608 с.

3. Савченко Т.В., Застрижная О.М., Климов В.В. Оксилипины и устойчивость растений к абиотическим стрессам // Бохимия. 2014. Т. 79 (4). С. 458-475.

4. Bisignano G., Lagana M.G., Trombetta D. et al. In vitro antibacterial activity of some aliphatic aldehydes from Olea europaea L. // FEMS microbiology letters 2001. V. 198 (1). P. 9-13.

5. Buseman C.M., Tamura P., Sparks A.A., et al. Wounding Stimulates the Accumulation of Glycerolipids Containing Oxophytodienoic Acid and Dinor-Oxophytodienoic Acid in Arabidopsis Leaves // Plant Physiol. 2006. V. 142. P. 28-39. https://doi.org/10.1104/pp.106.082115

6. Chen Q., Sun, J., Zhai, Q., et al. The basic helix-loop-helix transcription factor MYC2 directly represses PLETHORA expression during jasmonate-mediated modulation of the root stem cell niche in Arabidopsis // The Plant Cell. 2011. V. 23 (9). P. 3335-3352. https://doi.org/10.1105/tpc.111.089870

7. Cheong Y.H., Chang H.S, Gupta R., et al. Transcriptional Profiling Reveals Novel Interactions between Wounding, Pathogen, Abiotic Stress, and Hormonal Responses in Arabidopsis // Plant Physiol. 2002. V. 129. P. 661-677. https://doi.org/10.1104/pp.002857

8. Coutinho T. A., Preisig O., Mergaert J., et al. Bacterial blight and dieback of Eucalyptus species, hybrids, and clones in South Africa // Journal of General Plant Pathology. 2002. V. 86 (1). P. 20-25.https://doi.org/10.1094/PDIS.2002.86.1.20

9. Gorina S. S., Toporkova Y.Y., Mukhrarova L.S. et al. Oxylipin biosynthesis in spikemoss Selaginella moellendorffii: molecular cloning and identification of divinyl ether synthases CYP74M1 and CYP74M3 // BBA-Molecular and Cell Biology of Lipids. 2016. V. 1861 (4). P. 301-309. https://doi.org/10.1016/j.bbalip.2016.01.001

10. Goszczynska T., Ventera S. N., Coutinho T. A. PA 20, a semi-selective medium for isolation and enumeration of Pantoea ananatis // Journal of Microbiological Methods. 2006. V. 64 (2). P. 225-231. https://doi.org/10.1016/j.mimet.2005.05.004

11. Itoh A., Schilmiller A. L., McCaig B.C., Howe G.A. Identification of a jasmonate-regulated allene oxide synthase that metabolizes 9-hydroperoxides of linoleic and linolenic acids // The Journal of Biological Chemistry. 2002. V. 277. P. 46051-46058. 
12. Kourtchenko O., Andersson M.X., Hamberg M. et al. Oxo-phytodienoic acid-containing galactolipids in Arabidopsis: Jasmonate signaling dependence // Plant Physiol. 2007. V. 145. P. 1658-1669. https://doi.org/10.1104/pp.107.104752

13. Stintzi A., Browse J.The Arabidopsis male-sterile mutant, opr3, lacks the 12oxophytodienoic acid reductase required for jasmonate synthesis // Proceedings of the National Academy of Sciences. 2000. V. 97 (19). P. 10625-10630.

14. Toporkova Y. Y., Fatykhova V.S., Gorina S.S. et al. Epoxyalcohol synthase RjEAS (CYP74A88) from the Japanese buttercup (Ranunculus japonicus): cloning and characterization of catalytic properties // Biochemistry (Moscow). 2019. V. 84 (2). P. 171-180.

15. Toporkova Y.Y., Gorina S.S., Bessolitsyna E.K. et al. Double function hydroperoxide lyases/epoxyalcohol synthases (CYP74C) of higher plants: identification and conversion into allene oxide synthases by site-directed mutagenesis // BBA-Molecular and Cell Biology of Lipids. 2018. V. 1863. P. 369-378. https://doi.org/10.1016/j.bbalip.2018.01.002

16. Vancanneyt, G., Sanz, C., Farmaki, T. et al. Hydroperoxide lyase depletion in transgenic potato plants leads to an increase in aphid performance // Proceedings of the National Academy of Sciences. 2001. V. 98 (14). P. 8139-8144.

17. Zimmerman D. C., Coudron C. A. Identification of traumatin, a wound hormone, as 12-oxotrans-10-dodecenoic acid // Plant Physiology. 1979. V. 63 (3). P. 536-541. 